\title{
An Update on Cardiac Magnetic Resonance Imaging in Takotsubo Cardiomyopathy
}

\author{
Maheshi Y. Gunasekara $^{1}$ - Alice M. Mezincescu ${ }^{1} \cdot$ Dana K. Dawson ${ }^{1}$
}

Published online: 29 April 2020

(C) The Author(s) 2020

\begin{abstract}
Purpose of Review To provide an update on the use of cardiac magnetic resonance imaging in the diagnosis of Takotsubo cardiomyopathy.

Recent Findings Long-term prognosis of Takotsubo cardiomyopathy may not be as clear-cut as previously thought. Cardiac magnetic resonance imaging not only allows differentiation between reversible and nonreversible changes but has an emerging role in identifying cellular level changes associated with prognostic indicators such as myocardial energetics using ${ }^{31} \mathrm{P}-\mathrm{CMR}$ spectroscopy and detection of myocardial inflammation overlying myocardial oedema, using ultrasmall paramagnetic iron oxide particle uptake in macrophages.

Summary Takotsubo cardiomyopathy is a non-ischemic acute heart failure syndrome. It is commonly triggered by emotional or physical stress and is possibly the strongest psychosomatic interaction seen in medicine. While clinically its presentation mimics a myocardial infarction, the acute imaging characteristics are critical in correctly identifying the disease entity.
\end{abstract}

Keywords Stress cardiomyopathy $\cdot$ Takotsubo $\cdot$ Chest pain $\cdot$ Cardiac MRI

\section{Introduction}

Takotsubo cardiomyopathy, also known as acute stressinduced cardiomyopathy, apical ballooning and broken heart syndrome, was first described in 1990 in Japan by Sato et al. Takotsubo cardiomyopathy mimics acute coronary syndromes, presenting with symptoms, ECG changes and elevated biomarker levels that are indistinguishable from an acute myocardial infarction. However, the imaging characteristics and coronary angiography findings set it apart. As clinicians become more aware of this disease entity, there has been an exponential increase in its diagnosis [1]. Imaging in Takotsubo has evolved hugely over the last decade with cardiac magnetic resonance (CMR) imaging being the front runner in terms of detection of myocardial oedema and

This article is part of the Topical Collection on Cardiac Magnetic Resonance

Maheshi Y. Gunasekara

maheshi.gunasekara1@abdn.ac.uk

1 Medical Sciences and Nutrition, University of Aberdeen, Aberdeen, UK inflammation, fibrosis and cardiac energetic status in addition to accurate cine imaging for ventricular volumes and mass.

The objective of this review is to present current medical literature and evidence for the place of CMR in diagnosis of Takotsubo, in unravelling its pathophysiology and informing on the convalescent and long-term phases of the disease.

\section{Proposed Pathophysiological Mechanism of Takotsubo Cardiomyopathy}

To date, the exact pathogenic mechanism of this syndrome remains unclear; however, several hypotheses have been proposed involving vascular mechanisms (i.e. abnormal coronary epicardial or microvascular vasoreactivity) [2-4], endocrine and gender-related mechanisms (i.e. oestrogen deficiency) and both autonomic and central nervous system abnormalities involving possible catecholamine surges $[5,6]$, suggesting the possibility of a multifactorial pathogenic background.

\section{Incidence, Clinical Presentation and Diagnosis}

Takotsubo syndrome is estimated to represent approximately $1-3 \%$ of all [7] and 5-6\% of the female patients presenting with suspected acute myocardial infarction $[8,9]$. 
The diagnosis of Takotsubo has evolved in the past decade. Initially, Mayo Clinic criteria proposed the combination of the following: (1) transient, reversible regional wall motion abnormalities of the left ventricle (LV) extending beyond a single epicardial coronary vascular distribution; (2) absence of angiographic evidence of flow limiting coronary disease or acute plaque rupture; (3) new changes in electrocardiogram (ST segment elevation or T wave inversion); and (4) no recent significant head trauma, intracranial bleeding, pheochromocytoma, obstructive epicardial coronary artery disease (CAD), myocarditis and hypertrophic cardiomyopathy [10]. However, these have gradually evolved, and currently, the European Society of Cardiology has developed new international diagnostic criteria (InterTAK Diagnostic Criteria). These pertain mainly to the addition of the fact that the presence of CAD should not be considered as an exclusion criterion and is an important recognized bystander. In such patients, the wall motion abnormalities may extend beyond the territory of the diseased coronary artery. Takotsubo may also co-exist with acute coronary syndromes [11], and in some cases, acute coronary syndromes may trigger the onset of Takotsubo [12•]. A second important addition to the guidelines is the recognition that Takotsubo can co-exist with pheochromocytoma. Pheochromocytoma is a neuroendocrine disorder which may lead to a catecholamine storm with LV dysfunction, ECG abnormalities, elevated cardiac biomarkers as well as wall motion abnormalities which may be difficult to differentiate from Takotsubo. Furthermore, an additional clinical phenotype, the focal Takotsubo involving a single myocardial segment, has also been recognized [13].

\section{Cardiac MRI}

Over the last decade, CMR has become the key diagnostic modality in tertiary care centres for patients with suspected Takotsubo. Typically, this is carried out on clinical field strength scanners at $1.5 \mathrm{~T}$ or $3 \mathrm{~T}$.

CMR is indicated in all patients presenting with suspected Takotsubo; however, this is difficult to schedule in a timely manner in busy clinical settings. Therefore, diagnostic and management algorithms have been generated to help guide clinical decision-making. While risk stratification is essential to select patients, given the absence of evidence from large randomized control trials, the algorithms are based on expert consensus and require validation. Patients presenting with myocardial infarction and unobstructed coronary arteries (MINOCA) or without a clear culprit remain a diagnostic challenge, and timely CMR in this subgroup has shown higher prevalence of Takotsubo $[14,15]$. In these, the presence of an increased left ventricular mass, presence of intense myocardial oedema and lack of any late gadolinium enhancement are strongly in favour of a Takotsubo diagnosis.
It is the practice of the authors' institution that patients with troponin positive chest pain and absence of a clear culprit lesion on coronary angiogram are further risk stratified based on left ventriculogram and echocardiogram and specifically those with atypical ballooning patterns are fast tracked to early CMR. ECG changes in the post-acute phase with significantly greater $\mathrm{T}$ wave amplitude which is also widespread in a 12lead ECG 24-48 h after presentation, accompanied by increases in QTc interval which is also a valuable tool in differentiating Takotsubo from MI [16]. ST depression in aVR and absence of ST elevation in V1 has been shown to suggest Takotsubo with sensitivity and specificity of $>90 \%$ [17]. Troponin elevation is usually disproportionally low to the extent of the myocardium involved, while NT-proBNP levels are higher at admission compared with acute coronary syndromes [18]. International expert consensus document provides a comprehensive diagnostic algorithm which can be used to differentiate Takotsubo vs acute coronary syndromes or myocarditis [19].

\section{General Utility and Sequences Used}

Cardiovascular magnetic resonance imaging is uniquely suited for the evaluation of patients with Takotsubo. In addition to accurate visualization of regional wall motion abnormalities, it allows for precise quantification of right ventricular (RV) and LV function and the assessment of other abnormalities (e.g. pericardial and pleural effusion, LV and RV thrombi). Importantly, CMR imaging also allows differentiation of reversible (inflammation, oedema) and irreversible (necrosis, fibrosis) injury, which may be particularly important to verify Takotsubo and to exclude similar acute cardiac diseases such as myocardial infarction or myocarditis [20].

Due to its versatility, several sequences have become a routine in the clinical investigation of Takotsubo, while others have been tested in the clinical research environment only. For clinical assessment, steady-state free precession imaging is used for volumetric assessment of the cardiac chambers and appreciation of segmental wall motion abnormalities. T2weighted imaging (T2W) with fat suppression (triple inversion recovery) is utilized for qualitative assessment of myocardial oedema. Further, T1 and T2 myocardial mapping are used for quantification of oedema during the acute phase of the disease. T1 mapping is also used for quantification of myocardial fibrosis once the myocardial oedema has subsided. Early gadolinium enhancement (EGE) is utilized to identify LV thrombi, whereas late gadolinium enhancement (LGE) images acquired 10-20 min after administration of contrast are used to rule out myocardial infarction or any other macroscopic fibrosis patterns that would point out to a different pathology. In clinical research, cardiac ${ }^{31} \mathrm{P}$-magnetic resonance spectroscopy has been used to assess the cardiac energetic status, and $\mathrm{T} 2 *$-based sequences have identified 
myocardial inflammation by tracking ultrasmall iron oxide particles phagocytosed by activated macrophages in the myocardium.

\section{Functional Assessment}

Left Ventricular Function and Typical Wall Motion Abnormalities One of the most relevant features and a key diagnostic criterion of Takotsubo cardiomyopathy is the reversibility of the regional wall motion abnormalities of the LV that extend beyond a single epicardial vascular distribution. Characteristically the initial dyskinesia affects the apex and to various extent the mid-myocardial segments (anterior and septal segments always appear to be involved, whereas the mid-cavity posterolateral wall appears less affected). This is known as the classical "apical ballooning", and a complementary characteristic is the presence of basal hyperkinesia, further contributing to the characteristic morphology. However, other contraction patterns during the acute phase of Takotsubo may be present, and identification of other less common phenotypes (mid-cavity, basal or focal) has been described. In particular, the mid-cavity type, when seen, is quite pathognomonic for the disease. The basal or "inverted" variants (basal akinesis with mid ventricular and apical sparing) has also been reported and is characterized by basal hypokinesia and apical hypercontractility [21, 22]. Interestingly, the basal pattern has been associated with pheochromocytoma-induced Takotsubo and a younger age at presentation [23].

The classical apical variant can be accompanied by a dynamic obstruction in the LV outflow tract with or without systolic anterior motion of the mitral leaflets and/or functional mitral valve regurgitation. In the early days of diagnosing Takotsubo, it was not uncommon to misdiagnose these cases as hypertrophic cardiomyopathy. Characteristic for all Takotsubo phenotypes is the spontaneous recovery of wall motion abnormalities to normal or near normal ejection fraction in a matter of days to a few weeks; therefore, repeat imaging constitutes now a requirement for confirmation of diagnosis.

Right Ventricular Involvement Biventricular involvement is much more common than initially appreciated from echocardiography studies, due to the ability of CMR to visualize the RV in its entirety. Several reports showed that in Takotsubo patients presenting predominantly with ST elevation electrocardiogram, RV functional involvement was identified in approximately half $[24,25]$. RV involvement was also associated with longer hospitalization, worse markers of heart failure and older age [25].

Atrial Involvement CMR allows additionally for the assessment of the atrial function with the use of left atrial (LA) functional indexes. Compared with anterior ST elevation myocardial infarction, Takotsubo patients demonstrated a significantly worse LA function as assessed by CMR volumetric indexes derived from fractional volume changes during the acute phase of the disease. Impairment of LA performance seems to be transient in Takotsubo with full recovery seen during follow-up [26].

Feature Tracking CMR Feature tracking CMR (CMR-FT) is a novel technique which allows quantification of motion and strain using standard cine sequences of ventricular functional protocol. Abnormal global and regional strain patterns during the acute phase of Takotsubo that improved over time have been described by 2D echocardiography [27]. CMR-FT has been utilized to assess the diagnostic and prognostic potential of atrial involvement in Takotsubo and has demonstrated transient impairment in left atrial reservoir and conduit functions [28].

CMR-FT also has a place in assessing dys-synchrony and rotational mechanics in acute and during the clinical course of Takotsubo. Essentially desynchrony was shown to be increased in acute phase of Takotsubo, more pronounced in apical ballooning and seen in recover over time. CMR-FT may offer a reliable guide to improved pathophysiological evaluation of Takotsubo through rotational mechanics and dys-synchrony [29].

\section{Tissue Characterization: Myocardial Oedema and Inflammation}

T2W CMR is the standard imaging technique for detecting acute myocardial oedema [30, 31]. Black-blood T2W TripleIR [32] provides contrast between regional oedema and normal myocardium due to the dual suppression of the fat and flowing blood signal. Each tissue type exhibits a characteristic range of normal $\mathrm{T} 1$ and $\mathrm{T} 2$ relaxation times at a specific magnetic field strength.

Neil et al. found that increased T2W signal intensity, particularly at the apical cavity in apical Takotsubo patients, which persisted after 3 months, was inversely related to myocardial strain $[33,34]$. The amount of myocardial oedema seen in acute Takotsubo is unprecedented and causes an acute increase in LV mass [35], which is another helpful diagnostic feature during acute presentation. Quantitative techniques such as T1 mapping have confirmed this intensity of the myocardial oedema seen in the acute phase $[35,36]$. In a multicentre study by Eitel et al., myocardial oedema was reported in $81 \%$ of patients; this most likely is related to the variability in time between imaging relative to the acute presentation or disease onset [37]. We have shown that the myocardial oedema is present in both ballooning and nonballooning segments [35] and also involves the right ventricle [24]. It appears therefore that Takotsubo is characterized by 
pan-myocardial oedema in the acute phase. Longitudinal studies demonstrated the presence of residual oedema at 4 months $[38 \bullet, 39 \bullet]$, and a recent clinical trial further reported that it is only after 5 months after the acute event that the LV oedema begins to dissipate [39•].

In the absence of a clear ischaemic or infectious insult, it is intriguing as to what underlies this intense myocardial oedema and what could be its cause. In a recent multicentre study, we showed that compared with control subjects, patients with Takotsubo cardiomyopathy had greater ultrasmall superparamagnetic iron oxide particle (USPIO) retention in both ballooning and non-ballooning LV during the acute phase. As USPIOs are phagocytosed exclusively by activated tissue macrophages and not by any other inflammatory cells, this study demonstrated conclusively that macrophages are the main cellular protagonists of the myocardial cellular inflammation in acute Takotsubo (in contrast to acute myocarditis which is lymphocyte-mediated). Additionally, serum interleukin- 6 and chemokine (C-X-C motif) ligand 1 concentrations and classic $\left(\mathrm{CD} 14^{++} \mathrm{CD} 16^{-}\right)$monocytes were increased, whereas intermediate $\left(\mathrm{CD} 14^{++} \mathrm{CD} 16^{+}\right)$and nonclassic $\left(\mathrm{CD} 14^{+} \mathrm{CD} 16^{++}\right)$monocytes were reduced in patients with Takotsubo cardiomyopathy. At 5 months follow-up, USPIO enhancement was no longer detectable in the LV myocardium, although elevations in serum interleukin- 6 concentrations and reductions in intermediate $\mathrm{CD} 14^{++} \mathrm{CD} 16^{+}$monocytes persisted. Therefore, Takotsubo cardiomyopathy is characterized by a myocardial macrophage inflammatory infiltrate, changes in the distribution of monocyte subsets and an increase in systemic pro-inflammatory cytokines. Many of these changes persisted for at least 5 months, suggesting a low-grade, chronic inflammatory state [39•]. Furthermore, post-mortem examination of human hearts from patients who died during the acute phase of the condition demonstrated that these macrophages are predominantly of M1, proinflammatory type, as opposed to the reparative M2 type [40॰]. The presence of M1 macrophages and the persistence of the intermediate $\left(\mathrm{CD} 14^{++} \mathrm{CD} 16^{+}\right)$monocyte subset at 5 months follow-up are strongly indicative of lesser repair and more pro-inflammatory state compared with similar stages of patients with acute myocardial infarction. This offers the explanation for the low-grade, chronic inflammatory substrate and the evolution of acute Takotsubo into a long-term heart failure phenotype [41•].

Further evidence of the different systemic inflammatory activation in Takotsubo and acute coronary syndromes has been demonstrated by Santoro et al. who compared circulating cytokine levels in acute and subacute phase of Takotsubo and acute coronary syndromes. Increased levels of anti-inflammatory interleukins were found in acute phase of Takotsubo, while high levels of IL-6 were found in acute and subacute phase of acute coronary syndromes [42].
These demonstrated differences in pro-inflammatory mediator profiles in the two conditions seem promising to research more targeted and novel therapeutic options.

Apico-basal myocardial oedema as evidenced by increased T2W signal in CMR has been shown to be correlating with the ischaemic Wellens type ECG changes seen in Takotsubo. The dynamic T waves change, and QTc prolongation likely reflects the repolarisation dispersion in apical and basal segments secondary to myocardial oedema [43].

\section{Early and Late Gadolinium Enhancement}

The use of EGE sequence, performed within 2 min after contrast agent infusion, can reveal intra-cavitary LV/RV thrombus which appears as a low signal intensity (no gadolinium uptake) relative to the intermediate signal of the myocardium and high intensity signal of the blood pool [44].

Late gadolinium enhancement has been one of the most studied areas of CMR in Takotsubo. Initially, it was believed that lack of LGE was necessary to diagnose Takotsubo and would thus help differentiate it from myocardial infarction, where LGE is always present in some degree/pattern, and myocarditis, where $88 \%$ of patients show a patchy type of LGE [11, 45]. Eventually, some isolated reports, and later on, more significant studies, showed that LGE can be seen in patients diagnosed with Takotsubo cardiomyopathy [37, $46,47]$. When the pattern of LGE overlaps with that seen in other conditions (ischemia, myocarditis), two possibilities remain as it is very difficult to say with certainty whether the LGE is part of the acute presentation (and therefore represents Takotsubo-inflicted myocardial injury) or whether it reflects a previous and different pathophysiology in the same patient (and therefore is independent of the Takotsubo cardiomyopathy altogether). Corroboration between clinical presentation, ECG, imaging and biomarker findings are essential to make the correct diagnosis. Figure $1 \mathrm{a}$ and $\mathrm{b}$ demonstrate an LGE pattern that overlaps with that seen in myocarditis or nonischemic cardiomyopathies. Figure $1 \mathrm{c}$ and d demonstrate patterns which can be seen in other types of non-ischemic cardiomyopathies.

However, in some rare occurrences, the pattern of LGE seen is uniquely observed in Takotsubo: a distinctive transmural band appearing at the hinge points between the dyskinetic ballooning segments and the hypercontractile segments (Fig. 1e-f) - probably representing high shear forces at the demarcating border between dyskinetic and hypercontractile myocardium resulting in traumatic myocyte death.

The importance of detecting LGE in Takotsubo patients relies on the observed association between the presence of LGE and poorer prognosis in both ischemic and nonischemic cardiomyopathies [47]. In a series of 20 patients with Takotsubo cardiomyopathy, it was observed that LGE was associated with an increased frequency of cardiogenic shock 


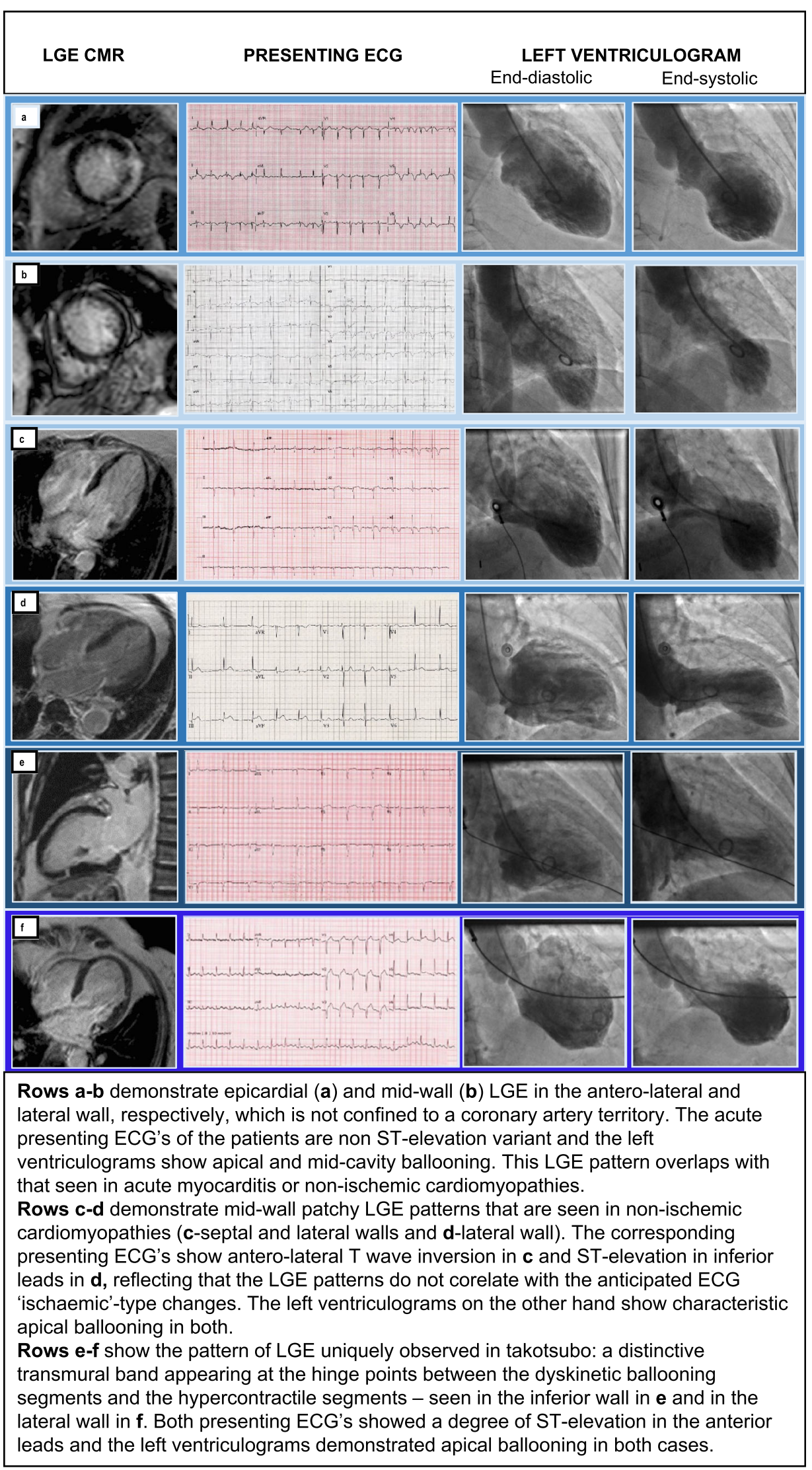

Fig. 1 Note: This data is mandatory. Please provide. 
and longer duration to ECG normalization [48]. In that same series and in another study, it was also observed that LGEpositive patients took longer to recover from the wall motion abnormalities [48, 49].

However, the main expected finding in the vast majority of clinical Takotsubo cases should be the absence of any LGE, which should remain a strong supporting finding for establishing the diagnosis.

\section{Cardiac Energetic Status}

Cardiac energetics (the $\mathrm{PCr} / \gamma$ ATP ratio obtained noninvasively by ${ }^{31} \mathrm{P}$-magnetic resonance spectroscopy) is severely reduced acutely in Takotsubo and only partly recovers by 4 months [35]. Furthermore, in a landmark cardiac phenotyping study, we demonstrated that patients with a prior episode of Takotsubo continue to have a significant degree of impairment in the cardiac energetic status long-term, which most likely represents the metabolic substrate of the heart failure phenotype that these patients appear to develop [41•].

\section{Complications and Long-Term Prognosis}

Possible complications in Takotsubo in the acute setting which include right ventricular involvement (18-34\%), left heart failure with or without pulmonary oedema (12-45\%), dynamic LVOT obstruction (10-25\%), mitral valve regurgitation (14-25\%), ventricular arrhythmias (4-9\%), intramural thrombus (2-8\%), pericardial effusion $(<1 \%)$, stroke [50], LV free wall rupture $(<1 \%)$ and death $[49,50,51 \bullet]$ have been described in the acute setting.

The long-term prognosis of patients with Takotsubo was initially thought to be favourable because of LV function recovery observed within several weeks to months [37]. Several small studies reported 15-17\% all-cause mortality after 2.94.7 years in Takotsubo patients $[52,53]$. The long-term mortality due to cardiovascular and non-cardiac causes are well documented [54-56]. Cardiogenic shock has been shown to be an important predictor in short- and long-term mortality in Takotsubo. Almendro et al. describe the subgroup of patients with cardiogenic shock as a high-risk phenotype with clustering of factors predisposing to heart failure. However, counterintuitively, long-term mortality in this subgroup of patients with cardiogenic shock was driven mainly by non-cardiac causes. This has raised the possibility of a vulnerable phenotype prone to heart failure [57, 58]. Even though large registry data [34] have now convincingly confirmed the poor longterm prognosis of Takotsubo patients, the actual cause of death in Takotsubo patients remains to be defined. This information will be instrumental in guiding therapies which address survival.

\section{Conclusions}

CMR offers a comprehensive, safe and reproducible assessment of the myocardial functional and anatomical properties, as well as of some of the potential complications of the syndrome, and has a complementary and additive role to the diagnosis of Takotsubo cardiomyopathy, once initial cardiac catheterisation has been carried out. As Takotsubo remains a diagnosis of exclusion, the information obtained from CMR adds in the workup and its differentiation from other acute entities with similar clinical presentation. Further large-scale studies are required to elucidate the exact clinical and prognostic value of CMR parameters in the management of the disease.

\section{Compliance with Ethical Standards}

Conflict of Interest The authors declare that they have no conflict of interest.

Human and Animal Rights and Informed Consent All reported studies/ experiments with human or animal subjects performed by the authors have been previously published and complied with all applicable ethical standards (including the Helsinki Declaration and its amendments, institutional/national research committee standards and international/national/institutional guidelines.)

Open Access This article is licensed under a Creative Commons Attribution 4.0 International License, which permits use, sharing, adaptation, distribution and reproduction in any medium or format, as long as you give appropriate credit to the original author(s) and the source, provide a link to the Creative Commons licence, and indicate if changes were made. The images or other third party material in this article are included in the article's Creative Commons licence, unless indicated otherwise in a credit line to the material. If material is not included in the article's Creative Commons licence and your intended use is not permitted by statutory regulation or exceeds the permitted use, you will need to obtain permission directly from the copyright holder. To view a copy of this licence, visit http://creativecommons.org/licenses/by/4.0/.

\section{References}

Papers of particular interest, published recently, have been highlighted as:

- Of importance

1. Khera R, Light-McGroary K, Zahr F, Horwitz PA, Girotra S. Trends in hospitalization for Takotsubo cardiomyopathy in the United States. Am Heart J. 2016;172:53-63.

2. Dote K, Sato H, Tateishi H, Uchida T, Ishihara M. Myocardial stunning due to simultaneous multivessel coronary spasms: a review of 5 cases. J Cardiol. 1991;21(2):203-14.

3. Kurisu S, Sato H, Kawagoe T, Ishihara M, Shimatani Y, Nishioka $\mathrm{K}$, et al. Takotsubo-like left ventricular dysfunction with STsegment elevation: a novel cardiac syndrome mimicking acute myocardial infarction. Am Heart J. 2002;143(3):448-55. 
4. Galiuto L, De Caterina AR, Porfidia A, Paraggio L, Barchetta S, Locorotondo G, et al. Reversible coronary microvascular dysfunction: a common pathogenetic mechanism in apical ballooning or Takotsubo syndrome. Eur Heart J. 2010;31(11):1319-27.

5. Wittstein IS, Thiemann DR, Lima JA, Baughman KL, Schulman SP, Gerstenblith G, et al. Neurohumoral features of myocardial stunning due to sudden emotional stress. N Engl J Med. 2005;352(6):539-48.

6. Abraham J, Mudd JO, Kapur NK, Klein K, Champion HC, Wittstein IS. Stress cardiomyopathy after intravenous administration of catecholamines and beta-receptor agonists. J Am Coll Cardiol. 2009;53(15):1320-5.

7. Prasad A, Dangas G, Srinivasan M, Yu J, Gersh BJ, Mehran R, et al. Incidence and angiographic characteristics of patients with apical ballooning syndrome (Takotsubo/stress cardiomyopathy) in the HORIZONS-AMI trial: an analysis from a multicenter, international study of ST-elevation myocardial infarction. Catheter Cardiovasc Interv. 2014;83(3):343-8.

8. Redfors B, Shao Y, Ali A, Omerovic E. Are the different patterns of stress-induced (Takotsubo) cardiomyopathy explained by regional mechanical overload and demand: supply mismatch in selected ventricular regions? Med Hypotheses. 2013;81(5):954-60.

9. Redfors B, Vedad R, Angeras O, Ramunddal T, Petursson P, Haraldsson I, et al. Mortality in Takotsubo syndrome is similar to mortality in myocardial infarction - a report from the SWEDEHEART registry. Int J Cardiol. 2015;185:282-9.

10. Bybee KA, Kara T, Prasad A, Lerman A, Barsness GW, Scott Wright R, et al. Systematic review: transient left ventricular apical ballooning: a syndrome that mimics ST-segment elevation myocardial infarction. Ann Intern Med. 2004;141(11):858-65.

11. Haghi D, Papavassiliu T, Hamm K, Kaden JJ, Borggrefe M, Suselbeck T. Coronary artery disease in Takotsubo cardiomyopathy. Circ J. 2007;71(7):1092-4.

12. Y-Hassan S, Tornvall P. Epidemiology, pathogenesis, and management of Takotsubo syndrome. Clin Auton Res. 2018;28(1):53-65.

13. Ghadri JR, Cammann VL, Napp L. Differences in the clinical profile and outcomes of typical and atypical Takotsubo syndrome. JAMA Cardiol. 2016;1(3):335-40.

14. Abanador-Kamper N, Kamper L, Castello-Boerrigter L, Haage P, Seyfarth M. MRI findings in patients with acute coronary syndrome and unobstructed coronary arteries. Diagn Interv Radiol. 2019;25(1):28-34.

15. Pathik B, Raman B, Mohd Amin NH, Mahadavan D, Rajendran S, McGavigan AD, et al. Troponin-positive chest pain with unobstructed coronary arteries: incremental diagnostic value of cardiovascular magnetic resonance imaging. Eur Heart J Cardiovasc Imaging. 2016;17(10):1146-52.

16. Scally C, Rudd A, Choo WK. Serial ECG characteristics in Takotsubo cardiomyopathy: comparison with myocardial infarction. Eur Heart J. 2017;38(1):6393.

17. Kosuge M, Ebina T, Hibi K, Morita S, Okuda J, Iwahashi N, et al. Simple and accurate electrocardiographic criteria to differentiate Takotsubo cardiomyopathy from anterior acute myocardial infarction. J Am Coll Cardiol. 2010;55(22):2514-6.

18. Frohlich GM, Schoch B, Schmid F, Keller P, Sudano I, Luscher TF, et al. Takotsubo cardiomyopathy has a unique cardiac biomarker profile: NT-proBNP/myoglobin and NT-proBNP/troponin T ratios for the differential diagnosis of acute coronary syndromes and stress induced cardiomyopathy. Int J Cardiol. 2012;154(3):328-32.

19. Ghadri JR, Wittstein IS, Prasad A, Sharkey S, Dote K, Akashi YJ, et al. International expert consensus document on Takotsubo syndrome (part II): diagnostic workup, outcome, and management. Eur Heart J. 2018;39(22):2047-62.

20. Eitel I, Behrendt F, Schindler K, Kivelitz D, Gutberlet M, Schuler $\mathrm{G}$, et al. Differential diagnosis of suspected apical ballooning syndrome using contrast-enhanced magnetic resonance imaging. Eur Heart J. 2008;29(21):2651-9.

21. Reuss CS, Lester SJ, Hurst RT, Askew JW, Nager P, Lusk J, et al. Isolated left ventricular basal ballooning phenotype of transient cardiomyopathy in young women. Am J Cardiol. 2007;99(10): 1451-3.

22. Van de Walle SO, Gevaert SA, Gheeraert PJ, De Pauw M, Gillebert TC. Transient stress-induced cardiomyopathy with an "inverted Takotsubo" contractile pattern. Mayo Clin Proc. 2006;81(11): 1499-502.

23. Y-Hassan S. Clinical features and outcome of pheochromocytomainduced Takotsubo syndrome: analysis of 80 published cases. Am J Cardiol. 2016;117(11):1836-44.

24. Scally C, Ahearn T, Rudd A, Neil CJ, Srivanasan J, Jagpal B, et al. Right ventricular involvement and recovery after acute stressinduced (Takotsubo) cardiomyopathy. Am J Cardiol. 2016;117(5): 775-80.

25. Haghi D, Athanasiadis A, Papavassiliu T, Suselbeck T, Fluechter S, Mahrholdt H, et al. Right ventricular involvement in Takotsubo cardiomyopathy. Eur Heart J. 2006 Oxford University Press;27(20):2433-9.

26. Stiermaier T, Santoro F, Eitel C, Graf T, Moeller C, Tarantino N, et al. Prevalence and prognostic relevance of atrial fibrillation in patients with Takotsubo syndrome. Int J Cardiol. 2017;245:156-61.

27. Heggemann F, Weiss C, Hamm K, Kaden J, Suselbeck T, Papavassiliu T, et al. Global and regional myocardial function quantification by two-dimensional strain in Takotsubo cardiomyopathy. Eur J Echocardiogr. 2009;10(6):760-4.

28. Backhaus SJ, Stiermaier T, Lange T, Chiribiri A, Uhlig J, Freund A, et al. Atrial mechanics and their prognostic impact in Takotsubo syndrome: a cardiovascular magnetic resonance imaging study. Eur Heart J Cardiovasc Imaging. 2019;20(9):1059-69.

29. Backhaus SJ, Stiermaier T, Lange T, Chiribiri A, Lamata P, Uhlig J, et al. Temporal changes within mechanical dyssynchrony and rotational mechanics in Takotsubo syndrome: a cardiovascular magnetic resonance imaging study. Int J Cardiol. 2018;273:256-62.

30. Friedrich MG. Myocardial edema - a new clinical entity? Nat Rev Cardiol. 2010;7:292-6.

31. Abdel-Aty H, Zagrosek A, Schulz-Menger J, Taylor AJ, Messroghli D, Kumar A, et al. Delayed enhancement and T2weighted cardiovascular magnetic resonance imaging differentiate acute from chronic myocardial infarction. Circulation. 2004;109: $2411-6$.

32. Aletras AH, Tilak GS, Natanzon A, Hsu LY, Gonzalez FM, Hoyt $\mathrm{RF} \mathrm{Jr}$, et al. Retrospective determination of the area at risk for reperfused acute myocardial infarction with T2-weighted cardiac magnetic resonance imaging: histopathological and displacement encoding with stimulated echoes (DENSE) functional validations. Circulation. 2006;113(15):1865-70.

33. Neil C, Nguyen T, Chapman M, Mahadavan G, Zeitz C, Horowitz J. Residual LV systolic dysfunction post-Takotsubo cardiomyopathy. Heart Lung Circ. 2012;21:S:258.

34. Neil C, Nguyen TH, Kucia A, Crouch B, Sverdlov A, Chirkov Y, et al. Slowly resolving global myocardial inflammation/oedema in Takotsubo cardiomyopathy: evidence from T2-weighted cardiac MRI. Heart. 2012;98(17):1278-84.

35. Dawson DK, Neil CJ, Henning A, Cameron D, Jagpal B, Bruce M, et al. Takotsubo cardiomyopathy: a heart stressed out of energy? Jacc Cardiovasc Imaging. 2015;8(8):985-7.

36. Ferreira VM, Piechnik SK, Dall'Armellina E, Karamitsos TD, Francis JM, Choudhury RP, et al. Non-contrast T1-mapping detects acute myocardial edema with high diagnostic accuracy: a comparison to T2-weighted cardiovascular magnetic resonance. $\mathrm{J}$ Cardiovasc Magn Reson. 2012;14:42.

37. Eitel I, von Knobelsdorff-Brenkenhoff F, Bernhardt P, Carbone I, Muellerleile K, Aldrovandi A, et al. Clinical characteristics and 
cardiovascular magnetic resonance findings in stress (Takotsubo) cardiomyopathy. JAMA. 2011;306(3):277-86.

38. Schwarz K, Ahearn T, Srinivasan J, Neil CJ, Scally C, Rudd A, et al. Alterations in cardiac deformation, timing of contraction and relaxation, and early myocardial fibrosis accompany the apparent recovery of acute stress-induced (Takotsubo) cardiomyopathy: an end to the concept of transience. J Am Soc Echocardiogr. 2017;30(8):745-55.

39. Scally C, Abbas H, Ahearn T, Srinivasan J, Mezincescu A, Rudd A, et al. Myocardial and systemic inflammation in acute stress-induced (Takotsubo) cardiomyopathy. Circulation. 2019;139(13):1581-92.

40. Wilson HM, Cheyne L, Brown PAJ, Kerr K, Hannah A, Srinivasan $\mathrm{J}$, et al. Characterization of the myocardial inflammatory response in acute stress-induced (Takotsubo) cardiomyopathy. JACC Basic Transl Sci. 2018;3(6):766-78.

41. Scally C, Rudd A, Mezincescu A, Wilson H, Srivanasan J, Horgan G, et al. Persistent long-term structural, functional, and metabolic changes after stress-induced (Takotsubo) cardiomyopathy. Circulation. 2018;137(10):1039-48.

42. Santoro F, Costantino MD, Guastafierro F, Triggiani G, Ferraretti A, Tarantino N, et al. Inflammatory patterns in Takotsubo cardiomyopathy and acute coronary syndrome: a propensity score matched analysis. Atherosclerosis. 2018;274:157-61.

43. Perazzolo Marra M, Zorzi A, Corbetti F, De Lazzari M, Migliore F, Tona F, et al. Apicobasal gradient of left ventricular myocardial edema underlies transient T-wave inversion and QT interval prolongation (Wellens' ECG pattern) in Takotsubo cardiomyopathy. Heart Rhythm. 2013;10(1):70-7.

44. Weinsaft JW, Cham MD, Janik M, Min JK, Henschke CI, Yankelevitz DF, et al. Left ventricular papillary muscles and trabeculae are significant determinants of cardiac MRI volumetric measurements: effects on clinical standards in patients with advanced systolic dysfunction. Int J Cardiol. 2008;126(3):359-65.

45. Haghi D, Fluechter S, Suselbeck T, Kaden JJ, Borggrefe M, Papavassiliu T. Cardiovascular magnetic resonance findings in typical versus atypical forms of the acute apical ballooning syndrome (Takotsubo cardiomyopathy). Int J Cardiol. 2007;120(2):205-11.

46. Avegliano G, Huguet M, Costabel JP, Ronderos R, Bijnens B, Kuschnir P, et al. Morphologic pattern of late gadolinium enhancement in Takotsubo cardiomyopathy detected by early cardiovascular magnetic resonance. Clin Cardiol. 2011;34(3):178-82.

47. Rolf A, Nef HM, Mollmann H, Troidl C, Voss S, Conradi G, et al. Immunohistological basis of the late gadolinium enhancement phenomenon in Takotsubo cardiomyopathy. Eur Heart J. 2009;30(13): 1635-42.

48. Nakamori S, Matsuoka K, Onishi K, Kurita T, Ichikawa Y, Nakajima $\mathrm{H}$, et al. Prevalence and signal characteristics of late gadolinium enhancement on contrast-enhanced magnetic resonance imaging in patients with Takotsubo cardiomyopathy. Circ J. 2012;76(4):914-21.

49. Naruse Y, Sato A, Kasahara K, Makino K, Sano M, Takeuchi Y, et al. The clinical impact of late gadolinium enhancement in Takotsubo cardiomyopathy: serial analysis of cardiovascular magnetic resonance images. J Cardiovasc Magn Reson. 2011;13:67429X-13-67.

50. De Backer O, Debonnaire P, Gevaert S, Missault L, Gheeraert P, Muyldermans L. Prevalence, associated factors and management implications of left ventricular outflow tract obstruction in Takotsubo cardiomyopathy: a two-year, two-center experience. BMC Cardiovasc Disord. 2014;14:147-2261-14-147.

51.• Templin C, Ghadri JR, Diekmann J, Napp LC, Bataiosu DR, Jaguszewski M, et al. Clinical features and outcomes of Takotsubo (stress) cardiomyopathy. N Engl J Med. 2015;373(10): 929-38.

52. Sharkey SW, Windenburg DC, Lesser JR, Maron MS, Hauser RG, Lesser JN, et al. Natural history and expansive clinical profile of stress (Takotsubo) cardiomyopathy. J Am Coll Cardiol. 2010;55(4): 333-41.

53. Elesber AA, Prasad A, Lennon RJ, Wright RS, Lerman A, Rihal CS. Four-year recurrence rate and prognosis of the apical ballooning syndrome. J Am Coll Cardiol. 2007;50(5):448-52.

54. Singh K, Neil CJ, Nguyen TH, Stansborough J, Chong CR, Dawson D, et al. Dissociation of early shock in Takotsubo cardiomyopathy from either right or left ventricular systolic dysfunction. Heart Lung Circ. 2014;23(12):1141-8.

55. Del PS, Parodi G, Bellandi B, Zampini L, Venditti F, Ardito M, et al. Anxiety trait in patients with stress-induced cardiomyopathy: a case-control study. Clin Res Cardiol. 2011;100(6):523-9.

56. Nunez-Gil IJ, Almendro-Delia M, Andres M, Sionis A, Martin A, Bastante T, et al. Secondary forms of Takotsubo cardiomyopathy: a whole different prognosis. Eur Heart J Acute Cardiovasc Care. 2016;5(4):308-16.

57. Almendro-Delia M, Nunez-Gil IJ, Lobo M, Andres M, Vedia O, Sionis A, et al. Short- and long-term prognostic relevance of cardiogenic shock in Takotsubo syndrome: results from the RETAKO registry. JACC Heart Fail. 2018;6(11):928-36.

58. Limite LR, Arcari L, Cacciotti L, Russo D, Musumeci MB. Cardiogenic shock in Takotsubo syndrome: a clue to unravel what hides behind the curtain? JACC Heart Fail. 2019;7(2):175-6.

Publisher's Note Springer Nature remains neutral with regard to jurisdictional claims in published maps and institutional affiliations. 